\title{
Stem Cells in Regenerative Medicine: Prospects and Pitfalls
}

\author{
Mehwish Zehravi, Osama Shahid, Ayesha Kashmala, Fareeha Faizan and Mohsin Wahid*
}

Stem Cells and Regenerative Medicine Lab., Dow Research institute of Biotechnology and Biomedical Sciences, Dow University of Health Sciences, Karachi, Pakistan.

\begin{abstract}
Stem cells are the cells that have the ability to regenerate themselves and are able to differentiate into one or more specialized cell types. This unique property makes them a valuable source for in vitro disease modeling, drug designing, regenerative medicine and tissue engineering. As no specie can fully mimic the human microenvironment, human cell models derived from patients cells provide a fascinating avenue for enhancing our current understanding of the early molecular stages of various diseases followed by validating therapeutics. In this paper, we reviewed the role of stem cells in regenerative medicine that includes use of cord blood derived stem cells in medicine and patient specific induced pluripotent stem cells for future transplant purposes and the hurdles and obstacles that we need to address before we can safely use these cells for patient cure.
\end{abstract}

Keywords: Cellular programming, Cord blood, Induced pluripotent stem cell, Regenerative medicine, Stem cells. doi.org/10.21089/njhs.23.0116

\section{INTRODUCTION}

Stem cells are cells that can divide to give rise to specialized progeny and simultaneously self-renew in order to maintain their own population. They may be classified according to their origin as embryonic stem cells (ESCs) present in the inner cell mass of a blastocyst and tissue stem cells (TSCs) that are present in several tissues in the human body including bone marrow, peripheral blood, skin, intestine, ovarian epithelium and testis. ESCs being pluripotent can give rise to all of the cells of the three germ layers while more specialized TSCs play a role in replacing old and damaged cells in the tissues in which they are present.

Regenerative medicine entails replacement, regeneration and engineering of cells, tissues or organs in order to establish normalcy of function or physiology [1]. For some congenital defects, injuries and genetic diseases, the field of clinical medicine currently offers mainly symptomatic therapy but regenerative medicine hopes to provide a cure.

The main objective of regenerative medicine is to develop novel therapies capable of replacing and restoring the functions of the tissues and organs within the human body. Globally, scientists are facing major challenges to explore the role of stem cells in human body and are working on crucial therapeutic strategies to treat diseased, injured or senile tissues, but they are coming across many obstacles in translating the in vitro science to in vivo environment to maximize the effect of cell-based therapies [2].

*Address correspondence to this author at the Stem Cells and Regenerative Medicine Lab., Dow Research Institute of Biotechnology and Biomedical Sciences, Dow university of Health Sciences, Karachi, Pakistan.

E-mail: mohsin.wahid@duhs.edu.pk
In this review we shall discuss the role of cord blood derived stem cells and patient specific induced pluripotent stem cells in regenerative medicine and the obstacles and pitfalls.

\section{HISTORY OF CELLULAR REPROGRAMMING}

In late 1950 early 1960s, Sir John Bertrand Gurdon was able to transfer the nucleus of a tadpole's intestinal cell into an enucleated fertilized tadpole egg to give rise to the tadpole 'Molly' [3]. This paved the way for the concept that process of differentiation does not cause a loss but merely different expression of the genes for pluripotency; hence the first cloned mammal 'Dolly': the sheep was born in 1996. Subsequently, in 2006, Dr. Shinya Yamanaka showed that it was possible to revert a mature differentiated cell back into an immature pluripotent state, so that it would behave like an embryonic stem cell [4, 5] (Fig. 1). This reprogrammed cell was called an 'induced pluripotent stem cell' (iPSC). These may be used inter-changeably for any of the applications of ESCs since they have been found to have similar expression patterns for pluripotency related genes and methylation patterns [6].

\section{CLASSIFICATION OF STEM CELLS}

Stem cells can be classified into embryonic stem cells and tissue stem cells based upon their source of origin [7]. Embryonic stem cells are derived from the inner cell mass of blastocyst and are pluripotent. However, their isolation leads to destruction of the embryo. In contrast, the tissue stem cells can be isolated from their respective tissues and are not pluripotent. These tissue stem cells play an important role in regeneration following injury [8]. 

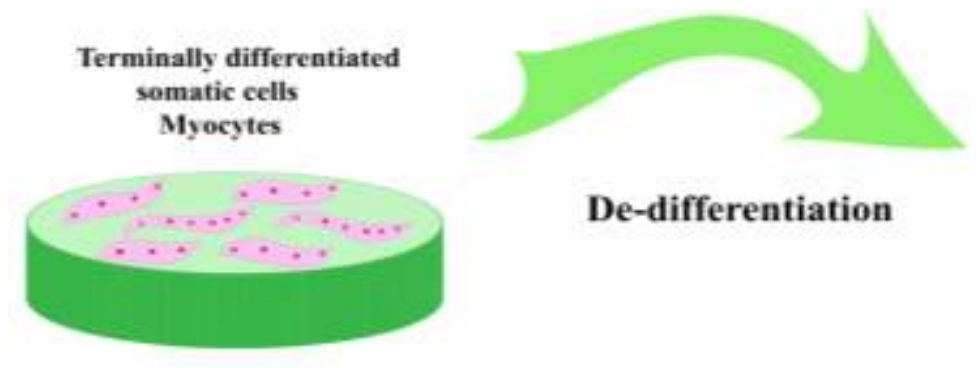

De-differentiation

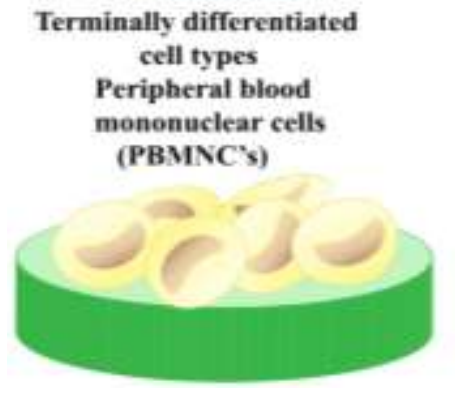

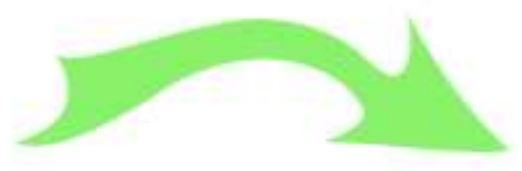

Transdifferentiation
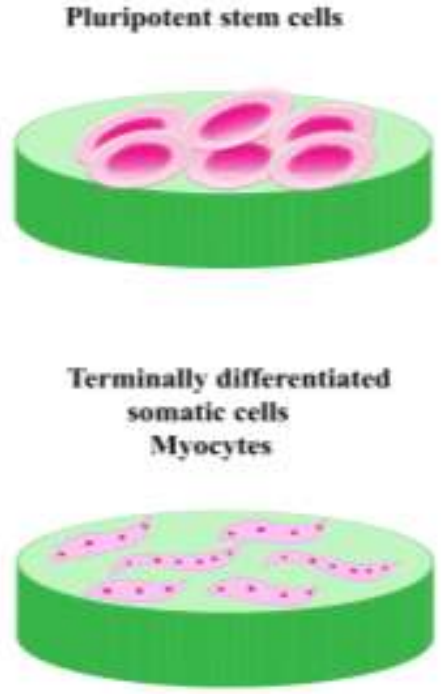

Fig. (1). Two types of cellular reprogramming strategies. De-differentiation involves reprogramming of adult cells towards pluripotency. Transdiffrentiation refers to transformation of one adult cell type to another without undergoing pluripotent state.

Based upon pluripotency, stem cells can be divided into embryonic stem cells and induced pluripotent stem cells. Due to ethical concerns with the use of embryonic stem cells, scientists have developed another way to generate induced pluripotent stem cells. Induced pluripotent stem cells are generated by forced expression of several genes and transcription factors [5].

\section{DISEASES FOR WHICH STEM CELL TRANS- PLANTATION HAS BEEN USED}

For most diseases curative treatment is still unavailable and the patients are maintained on supportive care. Stem cell discovery is a major breakthrough in the field of regenerative medicine. These cells have the capability to treat huge number of diseases. Hematopoietic stem cells in bone marrow transplantation were first used to treat hematological disorders. Bone marrow transplantation is now carried out routinely in hospitals for treatment of hematological disorders like leukemia while the other therapies for treatment of diseases are still in clinical trials.

Stem cell trials have been conducted for neurological diseases like Amyotrophic Lateral Selerosis (ALS) and spinal injuries. In phase I clinical trial, intra-spinal injections of human fetal neural stem cell into lumbar and cervical regions of spinal cord have been used in patients of amyotrophic lateral sclerosis [9]. The human fetal neural stem progenitor cells have been attempted for patients suffering from injuries of thoracic spine, particularly between T2-T11 thoracic level and subsequent improvement in sensory function observed. Few patients had minor improvement in motor function and rectal control [10]. Phase II clinical trials are being conducted for cervical spine injuries.
The autologous endothelial progenitor cells have been used to benefit patients with vascular disorders. These cells promote angiogenesis and have helped patients with refractory angina. The reduction in number of angina episodes adds up to the success of clinical trial [11]. Another trial has been conducted on patients with critical limb ischemia using autologous endothelial and hematopoietic progenitor cells with resulting improvement in symptoms [12, 13]. Bone marrow Mesenchymal Stem Cells (MSC) have also been attempted for transplantation in patients with critical limb ischemia but significant adverse effects have been noted [14].

The immunosuppressive properties of MSC have provided treatment options for many diseases. GVHD is a cause of high mortality in recipients of allogenic transplants. Prochymal MSC is the first stem cell therapy approved for treatment of steroid resistant, acute GVHD in pediatric patients reducing transplant related mortality and high survival rates [15]. The immunosuppressive property of MSC has also been employed for treatment of relapsing and remitting MS. In these cases either intra-thecal or intravenous injections of autologous MSC have been attempted resulting in slight reduction in inflammation seen on MRI scan [16].

Intra-articular injections of MSC have been shown to dramatically improve symptoms in patients of osteoarthritis [17]. Similarly, the patients with chronic back pain caused by degenerated disc diseases have shown improvement with injection of autologous expanded MSC. The cell therapy can be considered as an alternative to surgery in patients with intravertebral disc disease with subsequent relief in pain post surgery [18]. 


\section{STEM CELLS IN CLINICAL TRIALS}

The first clinical trial for patient specific iPSC was conducted in Japan for age related macular degeneration (AMD). The trial was initiated in 2013 with reprogramming of somatic cell to generate patient specific iPSCs. The iPSCs were differentiated into sheets of retinal pigment epithelium (RPE) cells. A 70-year-old lady with AMD underwent iPSC derived RPE transplant in 2014 which resulted in vision restoration. The second trial was postponed as mutation was detected in the next patient's iPSCs [10].

But, this is not possible for every type of tissue since, for example, tissue stem cells may not have been identified in that tissue, their attainment may be a high-risk procedure (as in the case of the heart) or they may fail to divide in vitro. In such situations, ESC and iPSCs play a promising role. This approach would also be appropriate for patients with retinal disorders whose limbal stem cells have been depleted.

Also ESCs and iPSCs may be used in vitro for creating 3D structures for replacing diseased or damaged tissues/organs for transplantation into a patient these seemingly straightforward applications are very challenging and complicated to carry out and much research is underway on bench-bedside transition for advancing the cause of many currently partly or entirely untreatable diseases like muscular dystrophies and spinal cord injuries $[19,20]$.

Some of the challenges include ethical issues attached with ESC use and so they may only be obtained from redundant embryos at IVF clinics. This also means that they are difficult to obtain, unsuitable for studying rare genetic disorders and allogenic; hence susceptible to rejection and entailing immunosuppression. This makes autologous iPSC a more appropriate choice. Yet, there are real issues of mutagenesis in iPSCs resulting in cancer and risk of pathogen (virus) transfer with allogeneic iPSC use.

Nevertheless, the translational field of regenerative medicine is currently growing at a monster pace and lots of new exciting avenues for research are opening up along the way. It has given us hope for the future cure of previously untreatable conditions and this gives strength and momentum to its advancement.

\section{INDUCED PLURIPOTENT STEM CELLS IN REGENERATIVE MEDICINE}

The use of induced pluripotent stem cells in regenerative medicine are manifolds. The applications of different cell therapies in clinical trials depend upon multiple factors like scalability, risks and safety profiles [21]. Limbal stem cells, neural stem cells, mesenchymal stem cells and pluripotent stem cells have promising role in regenerative medicine [10].
Ocular burns usually lead to destruction of transparent and avascular corneal epithelium resulting in blindness. Limbal stem cells hold the potential to regenerate corneal epithelium in patients with ocular burns [10].

Limbal stem cells derived from patient specific iPSCs can serve as potential source of cells for corneal regeneration and vision restoration in patients with ocular burns [10, 22].

Holoclar has been approved by European Medicine Agency as the first drug for treatment of burn associated blindness. It is suitable for treating moderate to severe limbal stem cell deficiency [10].

Retinitis pigmentosa is an inherited retinal disorder that leads to loss of photoreceptor cells and visual deterioration. IPSCs derived from patients of retinitis pigmentosa can be differentiated into rod photoreceptor cells following genome editing to correct the inherent mutation in these patients. This can provide a treatment option for the suffering patients [23].

\section{CORD BLOOD FOR REGENERATIVE MEDICINE}

An estimated yearly birth rate of more than 140 million births worldwide offers the umbilical cord blood (UCB) as a source for cells to be used in a wide variety of clinical conditions [24, 25]. Contrary to any unrelated donor cell, UCB is collected without any risk and non-invasively which can be cryopreserved for longer time without the loss of basic features like cell viability, functionality and have lower risk to transfer viral infections and mutations which causes complications to the patient after transplantation [25, 26]. Disadvantage of UCB includes cell dosage and delayed engraftment which are the main hurdles and the conventional UCBrelated treatment have restrictions whenever receivers are more and patients with known resistant to engraftment due to lower hematopoietic per UCB unit [25, 27-30].

\section{ISOLATED CELL TYPES FROM CORD BLOOD}

UCB contains hematopoietic progenitor cells (HPCs) as well as non-hematopoietic cells including mesenchymal stro$\mathrm{mal} / \mathrm{stem}$ cells (MSCs) and endothelial progenitor cells [25]. MSCs consist of multipotent progenitors which can be differentiated towards chondrogenic, osteogenic and adipogenic lineage and it is estimated that approximately $100 \mathrm{ml}$ of UCB contains 1000-5000 MSCs [31, 25]. Other population with different pluripotency potential can be derived from UCB includes unrestricted somatic stem cells (USSC) having the potential to differentiate into all three fates as observed [32].

Endothelial progenitor cells (EPCs) are another useful source found in $\mathrm{CB}$ having angiogenic properties, but there is no exact definition of an EPC and they can only be primarily distinct through the expression of cell-surface antigens based 
upon their clonogenic and proliferative potential. Some EPCs form colonies which can give rise to 100 population doublings, referred as high proliferative potential endothelial colony forming cells (HPP-ECFCs) upon replating produce secondary colonies stated as low proliferative potential endothelial colony forming cells (LPP-ECFCs) and tertiary colonies, referred as endothelial cell clusters (ECCs), are composed of less than 50 cells and cannot give rise to colonies upon replating. They have high levels of telomerase activity based upon their proliferative potential in human umbilical cord blood [33]. However, UCB is routinely used for hematopoietic stem cell transplantation in order to treat haematological conditions for a wide range of diseases but it can be used for regenerative cellular based treatment and immunomodulation [25, 34, 35]. There are some clinical studies that have already been done and some of them have been halted for some issues [25].

The discovery of iPSCs $[4,5]$ made the UCB as a beneficial source of juvenescent somatic cells to be used for reprogramming, making the UCB to be applied beyond the haematological disorders and iPSCs allows to produce organ from one's personal cells signifies for regenerative medicine $[36,37]$. Among other cell sources CB have several advantages including ease in collection, non-invasive, juvenescent cells source, acquire less somatic mutations as compare to adult cells, higher proliferation, rich in HSCs and easier to reprogram [38].

\section{LOCAL WORK RELATED TO REGENERATIVE MEDICINE IN PAKISTAN}

The field of regenerative medicine is at its beginning in Pakistan. Stem cell transplantation has been established only for hematological disorders. Allogenic bone marrow transplant has been established for aplastic anemia, $\beta$-thalassemia and hematological malignancies like AML at various hospitals like Agha Khan Hospital, Bismillah Taqee Institute of Health Sciences and Armed Forces Bone Marrow Transplant Centre in Pakistan [39].

\section{FUTURE PERSPECTIVES}

Over the last 10 years, regenerative medicine is proceeding with increasing information in cell fate but there are various issues to be addressed for clinical applicability [40]. Still, the cells isolated are majorly immature and give rise to heterogeneous cell population which causes complications inside the body as diseased organs rely upon numerous different functional cells and any transplantation of unauthentic cell may results in non-functionality or increase stimulation which can worsen the condition [40]. Along with it, the chances of teratogenicity and immune rejection should be excluded and in order to enhance cellular based therapy it is noteworthy to stimulate long-term graft [40, 41-43].
Clinical trials are going on to use the MSCs as antiinflammatory agents because of their immunomodulatory mechanisms in autoimmune disorders and inflammatory diseases [44]. MSCs have also been used in renal repair [45].

Senile muscular and skeletal disorders are global issues and important cause of morbidity which causes progressive degeneration of joints and bone with age, causing a patient to bear severe pain and various social and psychological problems Scientists are working world. Wide to discover cellbased treatments of these degenerative cartilage, joints and spinal diseases. MSCs have promising results in the application of these novel therapies. We cannot ignore the challenges that come across during invitro studies to isolate, culture, expand and differentiate the cells to particular lineage for the in vivo applications. The combination of biomaterials with cell-based therapies leads to a positive direction in the treatment of such disabling degenerative senile diseases [46]. For skin regeneration purposes three dimensional stem cell cultures are being established and their three dimensional printing to generate stem cell microenvironment engineered models are being used [47].

Induced pluripotent stem cells using $\mathrm{CB}$ can be used for disease modelling, drug discovery, drug screening, cell replacement therapy and tissue regeneration [48-58]. Due to many properties, $\mathrm{CB}$ is a valuable source for iPSCs production and approximately $80-100 \mathrm{ml}$ of CB contains about one billion cells which can be collected safely and easily from umbilical cord [59] and have promising future for regenerative and personalized medicine [48].

\section{OBSTACLES IN REGENERATIVE MEDICINE}

The course of scientific strategies that are being explored, from bench to bedside would be best achieved by combining academic and clinical research with industrial support. The lack of funding for these costly research studies is one of the obstacles to move forward in the field [60]. The ideas of preclinical trials are required to discover new efficient therapies and there is a need to have more industrial-scale approach that provide platform for association with more techniques to afford disease targeted research plans.

Other restrictions in regenerative medicine include the models for clinical trials like mice models that do not exactly mimic, human body in fact, there is no specie in the world that can exactly mimic the human microenvironment. The idea to create diseases in a dish using induced pluripotent stem cells to evaluate widely dissimilar constituents of human body, to understand mechanisms and genetic mutations that effects the system like central nervous system and cardiovascular system are new strategies to enhance the field [61].

Failure to suppress immunity in order to control graft rejection after allogenic stem cells transplant is a major obstruction to translate cell-based therapies. Scientists are working 
to control the response of immune rejection after transplantation [62].

\section{CONCLUSION}

In the current era of stem cell research, the clinical translation of therapies from bench towards bedside aims at establishing personalized approach for effective management and treatment of patients suffering from debilitating diseases. After laboratory research, extensive pre-clinical evaluation is required to assess the efficacy and safety of the product on invitro disease model before instigating it into human clinical trials. The implementation of therapies on humans as part of clinical trials is a multi-stage process that ultimately confirms the effectiveness of therapies [21].

A primary cell bank needs to be established for carrying out pre-clinical studies. These cell lines should be generated under good manufacturing practice (GMP) guidelines to guarantee that they are devoid of any pathogenic element [63].

The field of translational medicine is still in its naive state. Translation to clinical trials has been achieved for few diseases [21] mostly for eye diseases. The most favourable factor being limited number of cells required, easy accessibility to surgical procedures, easy visualization of cellular transplant and use of one eye as a control in bilateral disease [10].

Using patients own cells for transplantation can greatly reduce the risk of any immune reactions and iPS cells provide a good option as they can be differentiated to any human cell type required for the patient. However, a major obstacle in translating iPSC based therapies to clinical trial is the effective delivery of iPSC derived cells to the target organ [64].

\section{CONFLICT OF INTEREST}

Declared none.

\section{ACKNOWLEDGEMENT}

Declared none.

\section{REFERENCES}

[1] Zhang L, Webster TJ. Nanotechnology and nanomaterials: promises for improved tissue regeneration. Nano Today, 2009; 4(1): 66-80. DOI:10.1016/j.nantod.2008.10.014

[2] Dimmeler S, Ding S, Rando TA, Trounson A. Translational strategies and challenges in regenerative medicine. Nat. Med., 2014; 20(8): 814-21. DOI:10.1038/nm.3627

[3] Gurdon JB. Adult frogs derived from the nuclei of single somatic cells. Dev. Biol., 1962; 4(2): 256-73.

[4] Takahashi K, Yamanaka S. Induction of pluripotent stem cells from mouse embryonic and adult fibroblast cultures by defined factors. Cell, 2006; 126(4): 663-76. DOI: 10.1016/j.cell.2006.07.024

[5] Takahashi K, Tanabe K, Ohnuki M, Narita M, Ichisaka T, Tomoda $\mathrm{K}$, et al. Induction of pluripotent stem cells from adult human fibroblasts by defined factors. Cell, 2007; 131(5): 861-72. DOI: 10.1016/j.cell.2007.11.019

[6] Bock C, Kiskinis E, Verstappen G, Gu H, Boulting G, Smith ZD, et al. Reference maps of human ES and iPS cell variation enable highthroughput characterization of pluripotent cell lines. Cell, 2011; 144(3): 439-52. DOI: 10.1016/j.cell.2010.12.032

[7] Niwa H, Miyazaki J, Smith AG. Quantitative expression of oct-3/4 defines differentiation, dedifferentiation or self-renewal of ES cells. Nat. genet., 2000; 24(4): 372-6. DOI: 10.1038/74199

[8] Gardner RL. Stem cells: potency, plasticity and public perception. J. Anat., 2002; 200(3): 277-82.

DOI: $10.1046 / \mathrm{j} .1469-7580.2002 .00029 . \mathrm{x}$

[9] Feldman EL, Boulis NM, Hur J, Johe K, Rutkove SB, Federici T, et al. Intraspinal neural stem cell transplantation in amyotrophic lateral sclerosis: phase 1 trial outcomes. Ann. Neurol., 2014; 75(3): 363-73. DOI: 10.1002/ana.24113

[10] Trounson A, McDonald C. Stem cell therapies in clinical trials: progress and challenges. Cell Stem Cell, 2015; 17(1): 11-22. DOI: 10.1016/j.stem.2015.06.007.

[11] Jimenez-Quevedo P. Selected CD133+ progenitor cells to promote angiogenesis in patients with refractory angina. Circ. Res., 2014; 115(11): 950-60. DOI: 10.1161/CIRCRESAHA.115.303463

[12] Kawamoto A. Intramuscular transplantation of G- CSF- mobilized CD34+ cells in patients with critical limb ischemia: a phase I/IIa, multicenter, single-blinded, dose-escalation clinical trial. Stem Cells, 2009; 27(11): 2857-64. DOI: 10.1002/stem.207

[13] Kinoshita M, Fujita Y, Katayama M, Baba R, Shibakawa M, Yoshikawa $\mathrm{K}$, et al. Long-term clinical outcome after intramuscular transplantation of granulocyte colony stimulating factor-mobilized CD34 positive cells in patients with critical limb ischemia. Atherosclerosis, 2012; 224(2): 440-5.

DOI: http://dx.doi.org/10.1016/j.atherosclerosis.2012.07.031

[14] Gupta PK, Chullikana A, Parakh R, Desai S, Das A, Gottipamula S, et al. A double blind randomized placebo controlled phase I/II study assessing the safety and efficacy of allogeneic bone marrow derived mesenchymal stem cell in critical limb ischemia. J. Transl. Med., 2013; 11(1): 143. DOI: 10.1186/1479-5876-11-143

[15] Ratcliffe E, Glen KE, Naing MW, Williams DJ. Current status and perspectives on stem cell-based therapies undergoing clinical trials for regenerative medicine: case studies. Br. Med. Bull., 2013; 108(1): 73-94. DOI: https://doi.org/10.1093/bmb/ldt034

[16] Mohyeddin BM. Autologous mesenchymal stem cell therapy in progressive multiple sclerosis: an open label study. Curr. Stem Cell Res. Ther., 2012; 7(6): 407-14.

[17] Orozco L, Munar A, Soler R, Alberca M, Soler F, Huguet M, et al Treatment of knee osteoarthritis with autologous mesenchymal stem cells: a pilot study. Transplantation, 2013; 95(12): 1535-41. DOI: 10.1097/TP.0b013e318291a2da

[18] Orozco L, Soler R, Morera C, Alberca M, Sánchez A, GarcíaSancho J. Intervertebral disc repair by autologous mesenchymal bone marrow cells: a pilot study. Transplantation, 2011; 92(7): 822-8. DOI: 10.1097/TP.0b013e3182298a15

[19] Arimitsu N, Shimizu J, Iinuma M, Umehara T, Fujiwara N, Takai $\mathrm{K}$, et al. Human iPS cell derived neural cell sheets exhibit mature neural and extendable scaffold functions and promote recovery in injured mouse spinal cords. J. Stem. Cell. Res. Med., 2016; 1(2): 41-7. DOI: 10.15761/JSCRM.1000107

[20] Takano M, Kawabata S, Shibata S, Yasuda A, Nori S, Tsuji O, et al. Enhanced functional recovery from spinal cord injury in aged mice after stem cell transplantation through HGF induction. Stem Cell Rep., 2017; 8(3): 509-18. DOI: 10.1016/j.stemcr.2017.01.013 
[21] Trounson A, DeWitt ND. Pluripotent stem cells progressing to the clinic. Nat. Rev. Mol. Cell Biol., 2016; 17(3): 194-200. DOI:10.1038/nrm.2016.10

[22] Pellegrini G, De Luca M. Eyes on the prize: limbal stem cells and corneal restoration. Cell Stem Cell., 2014; 15(2): 121-2. DOI: 10.1016/j.stem.2014.07.011

[23] Yoshida T, Ozawa Y, Suzuki K, Yuki K, Ohyama M, Akamatsu W, et al. The use of induced pluripotent stem cells to reveal pathogenic gene mutations and explore treatments for retinitis pigmentosa. Mol. Brain., 2014; 7(1): 45. DOI: 10.1186/1756-6606-7-45

[24] Gluckman E, Ruggeri A, Volt F, Cunha R, Boudjedir K, Rocha V. Milestones in umbilical cord blood transplantation. $\mathrm{Br} . \mathrm{J}$. haematol., 2011; 154(4): 441-7. DOI: 10.1111/j.13652141.2011.08598.x

[25] Roura S, Pujal JM, Gálvez-Montón C, Bayes-Genis A.The role and potential of umbilical cord blood in an era of new therapies: a review. Stem Cell Res. Ther., 2015; 6(1): 123. DOI: 10.1186/S13287-015-0113-2

[26] Liao Y, Geyer MB, Yang AJ, Cairo MS. Cord blood transplantation and stem cell regenerative potential. Experimental Hematol., 2011; 39(4): 393-412.

DOI: http://dx.doi.org/10.1016/j.exphem.2011.01.002

[27] Jaroscak J, Goltry K, Smith A, Waters-Pick B, Martin PL, Driscoll TA, et al. Augmentation of umbilical cord blood (UCB) transplantation with ex vivo-expanded UCB cells: results of a phase 1 trial using the AastromReplicell System. Blood, 2003; 101(12): 5061-7. DOI: 10.1182/blood-2001-12-0290

[28] Hofmeister C, Zhang J, Knight KL, Le P, Stiff PJ. Ex vivo expansion of umbilical cord blood stem cells for transplantation: growing knowledge from the hematopoietic niche. Bone Marrow Transplant., 2007; 39(1): 11-23. DOI: 10.1038/sj.bmt.1705538

[29] Fares I, Chagraoui J, Gareau Y, Gingras S, Ruel R, Mayotte N, et al. Pyrimidoindole derivatives are agonists of human hematopoietic stem cell self-renewal. Science, 2014; 345(6203): 1509-12. DOI: $10.1126 /$ science. 1256337

[30] Bari S, Seah KKH, Poon Z, Cheung AMS, Fan X, Ong SY, et al. Expansion and homing of umbilical cord blood hematopoietic stem and progenitor cells for clinical transplantation. Biol. Blood Marrow Transplant., 2015; 21(6): 1008-19.

DOI: https://doi.org/10.1016/j.bbmt.2014.12.022

[31] Rogers I, Casper RF. Umbilical cord blood stem cells. Best Pract. Res. Clin. Obstet. Gynaecol., 2004; 18(6): 893-908. DOI: 10.1016/j.bpobgyn.2004.06.004

[32] Kögler G, Sensken S, Airey JA, Trapp T, Müschen M, Feldhahn $\mathrm{N}$, . et al. A new human somatic stem cell from placental cord blood with intrinsic pluripotent differentiation potential. J. Exp. Med., 2004; 200(2): 123-35. DOI: 10.1084/jem.20040440

[33] Ingram DA. Identification of a novel hierarchy of endothelial progenitor cells using human peripheral and umbilical cord blood. Blood. 2004; 104(9): 2752-60. DOI:10.1182/blood-2004-04-1396

[34] Ilic D, Miere C, Lazic E. Umbilical cord blood stem cells: clinical trials in non-hematological disorders. Br. Med. Bull., 2012; 102(1): 43-57. DOI: 10.1093/bmb/lds008

[35] Iafolla MA. Transplantation of umbilical cord blood-derived cells for novel indications in regenerative therapy or immune modulation: a scoping review of clinical studies. Biol. Blood Marrow Transplant., 2014; 20(1): 20-5.

DOI: $10.1016 /$ j.bbmt.2013.09.010

[36] Broxmeyer HE, Lee MR, Hangoc G, Cooper S, Prasain N, Kim YJ, et al. Hematopoietic stem/progenitor cells, generation of induced pluripotent stem cells, and isolation of endothelial progenitors from 21-to 23.5-year cryopreserved cord blood. Blood, 2011; 117(18): 4773-7. DOI: 10.1182/blood-2011-01-330514
[37] Hussein SM, Puri MC, Tonge PD, Benevento M, Corso AJ, Clancy $\mathrm{JL}$, et al. Genome-wide characterization of the routes to pluripotency. Nature, 2014; 516(7530): 198-206.

DOI: $10.1038 /$ nature 14046

[38] Eminli S, Foudi A, Stadtfeld M, Maherali N, Ahfeldt T, Mostoslavsky G, et al. Differentiation stage determines potential of hematopoietic cells for reprogramming into induced pluripotent stem cells. Nat. Genet., 2009; 41(9): 968-76. DOI: 10.1038/ng.428

[39] Shamsi T, Hashmi K, Adil S, Ahmad P, Irfan M, Raza S, et al. The stem cell transplant program in Pakistan-the first decade. Bone Marrow Transplant., 2008; 42(1): 114-7.

DOI: $10.1038 / \mathrm{bmt} .2008 .137$

[40] Hausburg F, David R. Regenerative medicine-from protocol to patient. New York: Springer; 2016 [cited 2017 Feb]. p. 455 Available from: DOI: 10.1007/978-3-319-27610-6

[41] Lensch MW. Teratoma formation assays with human embryonic stem cells: a rationale for one type of human-animal chimera. Cell Stem Cell, 2007; 1(3): 253-8. DOI: 10.1016/j.stem.2007.07.019

[42] Zhao T, Zhang ZN, Rong Z, Xu Y. Immunogenicity of induced pluripotent stem cells. Nature, 2011; 474(7350): 212-5. DOI:10.1038/nature10135

[43] Lang C, Lehner S, Todica A, Boening G, Zacherl M, Franz WM, et al. In-vivo comparison of the acute retention of stem cell derivatives and fibroblasts after intramyocardial transplantation in the mouse model. Eur. J. Nucl. Med. Mol. Imaging, 2014; 41(12): 2325-36. DOI: $10.1007 / \mathrm{s} 00259-014-2858-8$

[44] Kobolak J, Dinnyes A, Memic A, Khademhosseini A, Mobasheri A. Mesenchymal stem cells: identification, phenotypic characterization, biological properties and potential for regenerative medicine through biomaterial micro-engineering of their niche. Methods, 2015; 99: 62-8. DOI: 10.1016/j.ymeth.2015.09.016

[45] Morigi M, Rota C, Remuzzi G. Mesenchymal stem cells in kidney repair. Methods Mol. Biol., 2016; 1416: 89-107. DOI: 10.1007/9781-4939-3584-0_5

[46] Richardson SM, Kalamegam G, Pushparaj PN, Matta C, Memic A, Khademhosseini A, et al. Mesenchymal stem cells in regenerative medicine: focus on articular cartilage and intervertebral disc regeneration. Methods, 2016; 99: 69-80.

DOI: 10.1016/j.ymeth.2015.09.015

[47] Peerani R, Zandstra PW. Enabling stem cell therapies through synthetic stem cell-niche engineering. J. Clin. Invest., 2010; 120(1): 60-70. DOI: 10.1172/JCI41158

[48] El-Badri N. Advances in Stem Cell Therapy. Switzerland: Humana press; 2017 [cited Mar 2017]. 310 p. Available from: DOI: $10.1007 / 978-3-319-29149-9$

[49] Moretti A. Patient-specific induced pluripotent stem-cell models for long-QT syndrome. N. Engl. J. Med., 2010; 363(15): 1397-1409. DOI: 10.1056/NEJMoa0908679

[50] Itzhaki I, Maizels L, Huber I, Zwi-Dantsis L, Caspi O, Winterstern A, et al. Modelling the long QT syndrome with induced pluripotent stem cells. Nature, 2011; 471(7337): 225-9.

DOI: $10.1038 /$ nature09747.

[51] Matsa E, Rajamohan D, Dick E, Young L, Mellor I, Staniforth A, et al. Drug evaluation in cardiomyocytes derived from human induced pluripotent stem cells carrying a long QT syndrome type 2 mutation. Eur. Heart J., 2011; 32(8): 952-62.

DOI: 10.1093/eurheartj/ehr073

[52] Egashira T, Yuasa S, Suzuki T, Aizawa Y, Yamakawa H, Matsuhashi T, et al. Disease characterization using LQTS-specific induced pluripotent stem cells. Cardiovasc. Res., 2012; 95(4): 41929. DOI:https://doi.org/10.1093/cvr/cvs206 
[53] Lan F, Lee AS, Liang P, Sanchez-Freire V, Nguyen PK, Wang L, et al. Abnormal calcium handling properties underlie familial hypertrophic cardiomyopathy pathology in patient-specific induced pluripotent stem cells. Cell Stem Cell, 2013; 12(1): 101-13. DOI: 10.1016/j.stem.2012.10.010

[54] Ma D, Wei H, Zhao Y, Lu J, Li G, Sahib NB, et al. Modeling type 3 long QT syndrome with cardiomyocytes derived from patientspecific induced pluripotent stem cells. Int. J. Cardiol., 2013; 168(6): 5277-86. DOI: 10.1016/j.ijcard.2013.08.015

[55] Terrenoire C, Wang K, Tung KWC, Chung WK, Pass RH, Lu JT, et al. Induced pluripotent stem cells used to reveal drug actions in a long QT syndrome family with complex genetics. J. Gen. Physiol., 2013; 141(1): 61-72. DOI: 10.1085/JGP.201210899

[56] Han L, Li Y, Tchao J, Kaplan AD, Lin B, Li Y, et al. Study familial hypertrophic cardiomyopathy using patient specific induced pluripotent stem cells. Cardiovasc. Res., 2014; 104(2): 258- 69. DOI: $10.1093 / \mathrm{cvr} / \mathrm{cvu} 205$

[57] Doyle MJ, Lohr JL, Chapman CS, Nakagawa-Koyano N, Garry MG, Garry DJ. Human induced pluripotent stem cell-derived cardiomyocytes as a model for heart development and congenital heart disease. Stem Cell Rev. Rep., 2015; 11(5): 710-27. DOI: 10.1007/s12015-015-9596-6

[58] Park IH, Arora N, Huo H, Maherali N, Ahfeldt T, Shimamura A, et al. Disease-specific induced pluripotent stem cells. Cell, 2008; 134(5): 877-86. DOI: 10.1016/j.cell.2008.07.041.

[59] Rogers I, Holt D, MacPate F, Lains A, Hollowell S, Cruickshank B, et al. Human UC-blood banking: impact of blood volume, cell separation and cryopreservation on leukocyte and CD34+ cell recovery. Cytotherapy, 2001; 3(4): 269-76.

DOI: http://dx.doi.org/10.1080/146532401317070907

[60] Trounson A, Baum E, Gibbons D, Tekamp-Olson P. Developing a case study model for successful translation of stem cell therapies. Cell Stem Cell, 2010; 6(6): 513-6.

DOI: http://dx.doi.org/10.1016/j.stem.2010.05.008

[61] Bellin M, Marchetto MC, Gage FH, Mummery CL. Induced pluripotent stem cells: the new patient?. Nat. Rev. Mol. Cell Biol., 2012; 13(11): 713-26. DOI: $10.1038 / \mathrm{nrm} 3448$

[62] Chong JJ, Yang X, Don CW, Minami E, Liu YW, Weyers JJ, et al. Human embryonic-stem-cell-derived cardiomyocytes regenerate non-human primate hearts. Nature, 2014; 510(7504): 273-7. DOI: 10.1038/nature 13233

[63] Baghbaderani BA, Tian X, Neo BH, Burkall A, Dimezzo T, Sierra $\mathrm{G}$, et al. cGMP-manufactured human induced pluripotent stem cells are available for pre-clinical and clinical applications. Stem Cell Rep., 2015; 5(4): 647-59. DOI: 10.1016/j.stemcr.2015.08.015

[64] Hirschi KK, Li S, Roy K. Induced pluripotent stem cells for regenerative medicine. Annu. Rev. Biomed. Eng., 2014; 16: 277-94. DOI: 10.1146/annurev-bioeng-071813-105108

(C) 2017 National journal of health sciences.

This is an open-access article. 